\title{
Impact of nutritional support on nutritional status and nitrogen balance in surgical patients of a developing country
}

\author{
Ravindra Singh Mohil ${ }^{1 *}$, Nitisha Narayan ${ }^{1}$, Namrata Singh ${ }^{2}$, Asheesh Praveen Lal $^{1}$, \\ Vishnubhatla Sreenivas $^{3}$, Dinesh Bhatnagar $^{1}$ \\ ${ }^{1}$ Department of Surgery, V.M. Medical College and Safdarjang Hospital, New Delhi, India; \\ *Corresponding Author: rsmohil@gmail.com; \\ 101.nitisha@gmail.com, ashishplal@indiatimes.com, dineshbhatnagar d@ rediffmail.com \\ ${ }^{2}$ Department of Gastroenterology and Human Nutrition, AIIMS, New Delhi, India; namratasinghmohil@yahoo.com \\ ${ }^{3}$ Department of Biostatistics, AIIMS, New Delhi, India. sreenivas vishnu@yahoo.com
}

Received 4 September 2010; revised 8 October 2010; accepted 19 October 2010

\section{ABSTRACT}

To assess the nutritional status, its change after surgery and impact of nutritional support on urinary nitrogen losses (UNL) and nitrogen balance (NB) based on changing serum albumin levels in a developing country, 89 patient $(58 \mathrm{M})$ aged 39 yrs \pm 15 were studied. Nutritional assessment was done at admission and 2 weeks postoperatively. UNL and NB was assessed on postoperative day one (D1), two (D2), four (D4), six (D6), eight (D8) and eleven (D11) respectively. Malnutrition varied from $27(30.3 \%)$ using body mass index to $78(87 \%)$ by triceps skin fold thickness. Patients with falling or static serum albumin levels (Group I) showed a significant decrease (' $p$ ' $=0.001$ ) in their nutritional parameters compared to those with increasing albumin (Group II). Postoperatively till D2 both groups had similar negative NB but Group II improved earlier to become positively balanced by D11 ('p'< 0.001 ). Regression analysis of nitrogen intake (Ni) on UNL on each day revealed negative association till D2 to become positively associated from D4 onwards being significant on D4 ('p' $=0.001)$ \& D6 (' $p$ ' $\left.=0.05^{*}\right)$. There is a significant nutritional depletion after surgery especially in patients with falling/static serum albumin levels and NB improves earlier in patients with rising albumin levels. Increasing Ni helps in decreasing UNL.

Keywords: Nutritional Status; Nitrogen Balance; Serum Albumin

\section{INTRODUCTION}

In spite of India's rapid economic growth, adult malnutrition is still widely prevalent in the community. Defining malnutrition may be a challenge unless we realise what we actually mean by malnutrition. Prevalence of malnutrition depends upon the criteria used and nutritional status has been defined by multiple ways $[1,2]$. Different measures, different equipment and different formulae are being used, leading to different outcome both at individual and population level. Therefore applying western standards for nutritional assessment in developing countries may give misleading results.

Hospital under-nutrition, although recognised as of clinical significance, still remains widely undiagnosed/ underestimated even in the west where around $25 \%$ to $35 \%$ can be malnourished [3-5]. Besides nutritional deficiency, presence of inflammatory activity leads to loss of body cell mass (BCM) by inducing catabolism and both these factors combined lead to malnutrition [6]. In developing countries where under-nutrition is endemic and chronic infection is widely prevalent, malnutrition is more likely as both these factors operate simultaneously, strengthening each other and mutually aggravating their severity [7]. In first 3-5 days following surgery pro-inflammatory state is reversed by the ant-inflammatory healing response the adequacy of which can be judged based on negative fluid balance, increasing albumin, loss of edema, clinical improvement, increasing haemoglobin etc. Therefore, changing serum albumin levels is now being used more as an inflammatory marker than nutritional parameter [7]. Urinary nitrogen losses (UNL) and nitrogen balance (NB) reflect the intensity of this inflammatory response and has been widely used to monitor the adequacy of nutritional support postoperatively $[8,9]$. 
The present study was therefore undertaken to assess the nutritional status and its change in patients undergoing various types of surgeries in a developing country where malnutrition is endemic and nutritional standards are still not defined. The role of serum albumin as a marker of nutritional and inflammatory activity (increasing or decreasing/static) was studied. UNL and NB were studied to see loss patterns and when the pro-inflammatory state is being reversed in our group of patients. Based on changing albumin levels (inflammatory activity), NB pattern following surgery was also examined along with the impact of nitrogen intake (nutritional support) on UNL.

\section{MATERIALS AND METHODS}

Participants: The study was conducted in the surgical ward of a tertiary care, free, government hospital in the capital city of a developing country over a period of 18 months. The study was conducted according to the guidelines laid down in the Declaration of Helsinki and was approved by the hospital ethics committee. Witnessed verbal informed consent was obtained from all patients and formally recorded in the case sheet. Patients $<12$ years of age, those with enterocutaneous fistula, unconscious or clinically unstable, not taken up for surgery or died were excluded from the study.

Nutritional assessment: On admission a detailed clinical examination related to the main disease along with nutritional assessment was carried out. The nutritional assessment was performed within 48 hours of admission; using different nutritional indices. This included a detailed anthropometry, biochemical and immunological assessment. The assessment was repeated at two weeks postoperatively. Anthropometry using standard techniques included height, weight, body mass index (BMI), mid arm circumference (MAC) and triceps skin fold thickness (TSF). Mid arm muscle circumference (MAMC) was derived from the equation MAMC $=$ MAC- $\pi \times$ TSF. Biochemical assessment included haemoglobin, serum albumin (S. Albumin), creatinine height index (CHI). From the estimated 24 hours urinary creatinine excretion, creatinine height index (CHI) was calculated using the original standards of Bristrian (1976) [10]. Immunological parameters included total lymphocyte count (TLC) derived by multiplying total leucocyte count with percent lymphocyte count and delayed cutaneous hypersensitivity (DH). Purified protein derivative (PPD) one TU/0.1 ml was injected intradermally on the ventral aspect of forearm to measure delayed hypersensitivity response 48 hours.

Urinary Nitrogen loss \& Nitrogen balance: To calculate nitrogen intake protein content of various foods was seen from the tables of food composition of India
[11]. Twenty four hours urinary nitrogen loss was measured using the micro-Kjeldahl technique of total nitrogen assessment in the sample [12]. Nitrogen balance (NB) was calculated using the formula: $\mathrm{NB}=$ Nitrogen intake - Urinary Nitrogen loss $+1 \mathrm{~g} \times$ number of stools. [12]

Urinary Nitrogen loss (UNL) and NB was measured on postoperative day 1 (D1), 2 (D2), 4 (D4), 6 (D6), 8 (D8) and 11(D11). Protein intake was calculated by 24 hours recall method. The nitrogen intake was calculated using the formula:

$\mathrm{N} 2$ intake/day $=$ protein intake $(\mathrm{gms} /$ day $) / 6.25$

Nutritional categorisation: The anthropometric values were compared with percentages of normal values for age and sex. TSF values $<12.5 \mathrm{~mm}$ for males and $<16.5$ $\mathrm{mm}$ for females were taken as malnourished. The standard values for MAMC were $25.3 \mathrm{~cm}$ for males and 23.2 $\mathrm{cm}$ for females. Values were categorized as severe if $<$ $60 \%$ of standard, moderate $61-80 \%$ of standard and mild when $81-90 \%$ of standard. Values $>90 \%$ of standard were considered normal [13]. Body mass index which is derived by dividing body weight with height in meter square is a good indicator for nutritional assessment. It is increasingly being used for assessing and grading of nutritional status. Values $<18.5$ were categorized as malnourished, 18.5 to 25 were taken as normal and those with $>25$ were labeled as overweight.

Haemoglobin values in adult males of $<12 \mathrm{gm} \%$ and $<11.5 \mathrm{gm} \%$ in females were considered anaemic based on standard values [14]. Total lymphocyte count $>2000 /$ $\mathrm{mm}^{3}$ was considered normal, between $1200-1999 / \mathrm{mm}^{3}$ as mild depletion, 800-1199 as moderate depletion and those $<800$ as severely depleted [15]. Serum albumin $>$ 3.5 gm \% were considered normal. Concentrations between 2.8-3.5 gm \%, between 2.1-2.7 gm $\%$ and $<2.1$ gm $\%$ were categorized as mild, moderate and severe depletion respectively. [15] Standards laid down by Bristrian were followed to calculate creatinine height index (CHI) [10]. The response to intradermal injection of PPD antigen was evaluated at $48 \mathrm{hrs}$ after the test dose. Any induration $>5 \mathrm{~mm}$ and an erythema of more than 15-20 $\mathrm{mm}$ was considered positive [16]. Response other than this was considered negative.

Statistical Analysis: Data was entered into Microsoft Excel and Stata version 9.2 statistical software was used for data analysis. Descriptive statistics such as mean, standard deviation etc. for continuous covariates and percentage and proportions for categorical variables were reported. Independent t-test has been carried out for the comparison of continuous variables between two groups. The changes in various nutritional parameters before operation and after operation in the two groups, i.e. albumin decreasing/not changing and albumin increasing were compared using paired t-test. The direct association be- 
tween nitrogen balance (NB) and nitrogen intake (NI) cannot be studied because NB calculation involves NI. Therefore, the association between NI \& UNL was studied at different time points after surgery to see the dynamics of effect of NI on UNL. Simple linear regression analysis of UNL was carried out on $\mathrm{Ni}$ at each day for this purpose. Categorical variables were compared by Chisquare test or Fisher's exact test wherever applicable. Generalised Estimating Equation (GEE) has been applied to see the overall changes in UNL and NB over the time (D1 to D11). The level of significance was set at ' $p$ ' value $<0.05$

\section{RESULTS}

Sixteen patients out of 105 evaluated were excluded because of various reasons. Four patients had enterocutaneous fistula following surgery done outside, 5 patients were in ICU postoperatively for more than 5-7 days, five patients died and two patients left against medical advice before the study period was over. Out of the total 89 patients finally included in the study, 58 were males and 34 females. The mean age was 39.19 yrs +14.63 (range 17-80 year). For analysis patients were divided into two groups based on changing serum albumin levels into those with decreasing/static (Group I) or increasing (Group II) values.
Initial nutritional assessment: The prevalence of malnourished patients varied when different parameters were used for nutritional assessment. When BMI was used $27(30.3 \%)$ patients were found to be malnourished. This increased to a maximum of $78(87 \%)$ by TSF. The degree of malnutrition varied between these two extremes using other nutritional parameters as shown in Table1. Biochemical parameters like serum albumin and total lymphocyte count were lower than normal in 20 (22.47\%) and $48(53.93 \%)$ of the patients respectively on initial assessment. Only five (5.6\%) patients showed energy to PPD. Patients with BMI $<18.5$ had significantly lower nutritional parameters (Table 2).

Change in nutritional status: Postoperatively there was a significant decrease in various nutritional parameters of the whole group except serum albumin. Albumin decreased or remained same (Group I) in 66 (74.15\%) \& improved (Group II) in the remaining 23 (25.85\%) patients. At the end of two weeks, Group I patients had a significant decrease in their weight and all the other nutritional parameters. Compared to this, Group II patients showed improvement in all their other nutritional parameters although this was significant for weight, tsf and haemoglobin only (Table 3).

UNL \& NB: UNL were highest on day six (D 6) and returned to preoperative levels by approximately D11 for the whole group. UNL were depended on the extent and

Table 1 .Classification of subjects into various grades of nutritional status using different nutritional parameters.

\begin{tabular}{ccccc}
\hline \multirow{2}{*}{$\begin{array}{c}\text { Nutritional } \\
\text { parameter }\end{array}$} & \multicolumn{4}{c}{ Nutritional status } \\
\cline { 2 - 5 } & $\begin{array}{c}\text { Severe } \\
<60 \%\end{array}$ & $\begin{array}{c}\text { Moderate } \\
61-80 \%\end{array}$ & $\begin{array}{c}\text { Mild } \\
81-90 \%\end{array}$ & $\begin{array}{c}\text { Normal } \\
>90 \%\end{array}$ \\
\hline S. Albumin & 0 & $6(6.7)$ & $14(15.73)$ & $69(77.52)$ \\
TLC & $1(1.1)$ & $15(16.85)$ & $32(35.95)$ & $41(46.06)$ \\
TSF & $49(55.05)$ & $18(20.22)$ & $11(12.35)$ & $11(12.35)$ \\
MAMC & 0 & $15(16.85)$ & $26(29.21)$ & $48(53.93)$ \\
CHI & $4(4.44)$ & $37(41.57)$ & $20(22.47)$ & $28(31.46)$ \\
\hline
\end{tabular}

Values are given as numbers and percentages in parentheses

Table 2. Comparison of nutritional parameters based on BMI.

\begin{tabular}{|c|c|c|c|c|c|}
\hline \multirow{2}{*}{$\begin{array}{l}\text { Nutritional } \\
\text { parameter }\end{array}$} & \multicolumn{2}{|c|}{$\mathrm{BMI}<18.5(\mathrm{n}=27)$} & \multicolumn{2}{|c|}{$\mathrm{BMI}>18.5(\mathrm{n}=62)$} & \multirow{2}{*}{ 'p' value } \\
\hline & Normal & Undernourished & Normal & Undernourished & \\
\hline TSF & 0 & $27(100 \%)$ & $11(17.70 \%)$ & $51(82.3 \%)$ & $0.03 *$ \\
\hline MAMC & $7(25.9 \%)$ & $20(74.1 \%)$ & $42((67.7 \%)$ & $20(32.3 \%)$ & $<0.001 *$ \\
\hline Haemoglobin & $1(3.7 \%)$ & $26(96.27 \%)$ & $31(50 \%)$ & $31(50 \%)$ & $<0.001 *$ \\
\hline $\mathrm{DH}$ & $22(81.5 \%)$ & $5(18.5 \%)$ & $62(100 \%)$ & 0 & $0.01 *$ \\
\hline S. Albumin & $13(48.1 \%)$ & $14(51.85 \%)$ & $56(90.3 \%)$ & $6(9.67 \%)$ & $<0.001 *$ \\
\hline
\end{tabular}

*Significant 
Table 3. Comparison and change in nutritional parameters after surgery as compared to before surgery in patients with albumin falling/ no change (Group I) vs. those with rising albumin levels (Group II).

\begin{tabular}{|c|c|c|c|c|c|c|c|c|c|}
\hline \multirow{2}{*}{$\begin{array}{l}\text { Nutritional } \\
\text { parameter }\end{array}$} & \multicolumn{5}{|c|}{$\begin{array}{l}\text { Albumin- no change /falling Group I } \\
\qquad(\mathrm{n}=66)\end{array}$} & \multicolumn{4}{|c|}{$\begin{array}{l}\text { Albumin rising Group II } \\
\qquad(\mathrm{n}=23)\end{array}$} \\
\hline & Pre-op & Post -op & $\begin{array}{l}\mathrm{Ch} \\
\mathrm{Pos} \\
\left(95^{\circ}\right.\end{array}$ & $\begin{array}{l}\text { nge } \\
\text { Pre } \\
\left.\mathrm{CI}^{*}\right)\end{array}$ & 'p'value & Pre-op & Post-op & $\begin{array}{c}\text { Change } \\
\text { Post- Pre } \\
\left(95 \% \mathrm{CI}^{*}\right)\end{array}$ & 'p'value \\
\hline Weight & $\begin{array}{l}57.33 \\
\pm 8.50\end{array}$ & $\begin{array}{l}56.16 \\
\pm 8.49\end{array}$ & $\left(0.82^{1}\right.$ & $\begin{array}{l}7 \\
1.51)\end{array}$ & $0.001 *$ & $\begin{array}{l}48.10 \\
\pm 8.87\end{array}$ & $\begin{array}{l}48.84 \\
\pm 8.39\end{array}$ & $\begin{array}{c}-0.74 \\
(-1.49 \quad 0.01)\end{array}$ & $0.001 *$ \\
\hline MUAC & $\begin{array}{l}25.80 \\
\pm 2.91\end{array}$ & $\begin{array}{l}25.00 \\
\pm 3.28\end{array}$ & $(0.59$ & $1.01)$ & $0.001 *$ & $\begin{array}{l}22.15 \\
\pm 2.53\end{array}$ & $\begin{array}{l}22.46 \\
\pm 2.62\end{array}$ & $\left(\begin{array}{ll}-0.31 \\
-0.83^{0} & 0.21\end{array}\right)$ & $0.001 *$ \\
\hline TSF & $\begin{array}{c}0.82 \\
\pm 0.38\end{array}$ & $\begin{array}{l}0.73 \\
\pm 0.38\end{array}$ & $(0.06$ & $9.11)$ & $0.001 *$ & $\begin{array}{l}0.71 \\
\pm 0.46\end{array}$ & $\begin{array}{l}0.78 \\
\pm 0.45\end{array}$ & $\begin{array}{c}-0.06 \\
(-0.11 \quad-0.02)\end{array}$ & $0.01 *$ \\
\hline MAMC & $\begin{array}{l}23.29 \\
\pm 2.44\end{array}$ & $\begin{array}{l}22.78 \\
\pm 2.74\end{array}$ & $\left(0.23^{0}\right.$ & $0.79)$ & $0.001 *$ & $\begin{array}{r}19.89 \\
\pm 1.94\end{array}$ & $\begin{array}{l}20.13 \\
\pm 2.03\end{array}$ & $\begin{array}{c}-0.24 \\
(-0.84 \quad 0.36)\end{array}$ & 0.42 \\
\hline $\mathrm{CHI}$ & $\begin{array}{c}86.25 \\
\pm 25.04\end{array}$ & $\begin{array}{l}76.06 \\
\pm 13.57\end{array}$ & $\left(5.66^{1}\right.$ & $\begin{array}{l}19 \\
14.73)\end{array}$ & $0.001 *$ & $\begin{aligned} & 77.56 \\
\pm & 22.23\end{aligned}$ & $\begin{array}{c}77.77 \\
\pm 15.16\end{array}$ & $\begin{array}{c}-0.21 \\
(-6.49 \quad 6.07)\end{array}$ & 0.94 \\
\hline $\mathrm{Hb}$ & $\begin{array}{r}11.44 \\
\pm 1.52\end{array}$ & $\begin{array}{r}10.75 \\
\pm 1.63\end{array}$ & $\left(0.47^{0}\right.$ & $0.90)$ & $0.001 *$ & $9.91 \pm 1.75$ & $\begin{array}{l}10.92 \\
\pm 1.30\end{array}$ & $\begin{array}{c}-1.01 \\
(-1.39 \quad-0.63)\end{array}$ & $0.001 *$ \\
\hline TLC & $\begin{array}{l}2124 \\
\pm 602\end{array}$ & $\begin{array}{r}2029 \\
\pm 619\end{array}$ & $(50$ & 140) & $0.001 *$ & $\begin{array}{r}1629 \\
\pm 659\end{array}$ & $\begin{array}{r}1669 \\
\pm 603\end{array}$ & $\left(-118^{-40}-38\right)$ & 0.30 \\
\hline
\end{tabular}

CI - Confidence interval; *Significant

type of surgery. It was $<10 \mathrm{~g} / 24$ hours in thyroidectomy, appendectomy, hernia surgery and exploratory laprotomy. Moderate amount of nitrogen loss were seen in mastectomy (15 g/ 24 hours), pyelolithotomy (13 g/ 24 hours), gastrectomy, abdomino-perineal resection (19 g/ 24 hours), and Commando's operation (with radical neck dissection) (25 g/ 24 hours). It was very high after thoracotomy (45 g/ 24 hours) and Mc Keown esophagectomy (70 g/ 24 hours) done in two patients each respectively.

Nitrogen intake (NI) also influenced the mean UNL, from having no association on D1 to being negatively associated on D2, it improved D4 onwards to become positively associated till D11. As the nitrogen intake (NI) improved, UNL also improved, though this reached statistical significance on D4 \& D6 only (Table 4).

Similar to UNL, NB also became increasingly negative to reach a peak on D6, returning to starting D1 levels by D11. Compared to patients with falling or static S. Albumin (Group I), the NB started improving earlier in patients with rising S. Albumin (Group II). Initially till D2 there was no significant difference in the mean negative NB between the two groups, but D3 onwards Gr. II patients had lesser negative NB becoming positive by D11. This was borderline significant (' $p$ ' $=0.06$ ) on D4 and became increasingly significant thereafter till D11 (Table 5).

\section{DISCUSSION}

An ideal tool for nutritional assessment should be sensitive, accurate, reproducible by various observers, relevant in health and illness, applicable to all patients at the bedside, and cost-effective. The diagnosis of malnutrition is generally based on objective methods of nutritional assessment including assessment of dietary intake, weight loss, anthropometric data, determination of cell mediated immunity, biochemical parameters, body function and composition analysis [17,18]. Despite a large body of work on nutritional risk screening and assessment there is no complete agreement on the optimal method for either nutritional screening or assessment. This is due to lack of consensus regarding definitions and assessment of nutritional status.

Malnutrition has been defined in different ways. ESPEN consensus report defined it as "a state resulting from lack of intake of nutrition leading to altered body composition (decreased fat free mass (FFM) but specifically body cell mass (BCM)) and diminished function". [19] However, Norman et al [6] highlighted the role of inflammatory activity as a contributory factor to malnutrition leading to inclusion of metabolism as factor in defining malnutrition. Further, over-nutrition has not been included in the above definition. Based on these facts Soeters et al [7] have proposed that malnutrition may be defined as "a subacute or chronic state of nutrition in which a combination varying degrees of over- or undernutrition and inflammatory activity have led to a change in body composition and diminished function".

In a developing country like ours defining malnutrition may be a challenge as there is limited data on vari- 
ous nutritional parameters and the data collected in the

Table 4. Association between Nitrogen intake (Ni) \& Urinary Nitrogen Losses (UNL) day wise ( $\mathrm{n}=89$ ).

\begin{tabular}{|c|c|c|c|c|c|c|}
\hline Day of assessment & $\begin{array}{c}\mathrm{Ni} \\
\text { Mean } \pm \mathrm{SD}\end{array}$ & $\begin{array}{c}\text { UNL } \\
\text { Mean } \pm \text { SD }\end{array}$ & $\begin{array}{c}\text { Regression } \\
\text { Coefficient\# }\end{array}$ & \multicolumn{2}{|c|}{$95 \% \mathrm{CI}$} & 'p' value \\
\hline D 1 & $2.09 \pm 1.99$ & $7.26 \pm 0.37$ & -0.30 & $(-0.66$ & $0.07)$ & 0.11 \\
\hline D 2 & $0.27 \pm 0.85$ & $10.79 \pm 0.77$ & -2.36 & $(-4.18$ & $0.61)$ & $0.01 *$ \\
\hline D 4 & $4.10 \pm 7.72$ & $15.74 \pm 1.29$ & 0.74 & $(0.44$ & 1.04) & $0.001 *$ \\
\hline D 6 & $5.02 \pm 7.98$ & $17.18 \pm 1.51$ & 0.38 & $(0.003$ & $0.75)$ & $0.05 *$ \\
\hline D 8 & $5.98 \pm 8.74$ & $15.98 \pm 1.50$ & 0.15 & $(-0.20$ & $0.49)$ & 0.40 \\
\hline D 11 & $6.76 \pm 9.38$ & $12.26 \pm 1.03$ & 0.06 & $(-0.15$ & $0.29)$ & 0.55 \\
\hline
\end{tabular}

\#Regression coefficient of Ni on UNL; *Significant

Table 5. Change in Nitrogen Balance (NB) in the two groups based on changing albumin levels.

\begin{tabular}{|c|c|c|c|c|}
\hline \multirow[b]{2}{*}{ Day of assessment } & \multicolumn{2}{|c|}{ Nitrogen Balance } & \multirow[b]{2}{*}{ Difference $(95 \% \mathrm{CI})$} & \multirow[b]{2}{*}{ 'p'value - } \\
\hline & $\begin{array}{l}\text { Albumin } \downarrow \text { or } \\
\text { no change } \\
\text { (Group I) }\end{array}$ & $\begin{array}{c}\text { Alb. } \uparrow \\
\text { (Group II) }\end{array}$ & & \\
\hline D 1 & $-6.36 \pm 4.48$ & $-6.05 \pm 3.83$ & $\begin{array}{c}-0.31 \\
(-2.39 \quad 1.77)\end{array}$ & 0.77 \\
\hline D 2 & $-11.65 \pm 7.74$ & $-11.54 \pm 7.32$ & $\begin{array}{l}-0.11 \\
(-3.79 \quad 3.56)\end{array}$ & 0.95 \\
\hline D 4 & $-14.03 \pm 10.83$ & $-9.07 \pm 10.58$ & $\begin{array}{l}-4.96 \\
(-10.14 \quad 0.22)\end{array}$ & 0.06 \\
\hline D 6 & $-15.04 \pm 14.05$ & $-8.17 \pm 15.99$ & $\left(\begin{array}{ll}-6.87 \\
(-13.65 & 0.11)\end{array}\right.$ & $0.05^{*}$ \\
\hline D 8 & $-14.30 \pm 16.33$ & $-1.95 \pm 10.37$ & $\begin{array}{c}-12.34 \\
(-19.59 \quad-5.10)\end{array}$ & $0.001 *$ \\
\hline D 11 & $-10.13 \pm 12.28$ & $3.54 \pm 9.43$ & $\begin{array}{c}-13.67 \\
(-19.27 \quad-8.08)\end{array}$ & $<0.001^{*}$ \\
\hline
\end{tabular}

*Significant

community is anthropometric. The problem is further compounded by the presence of chronic energy deficiency syndrome (CED). [20] This has been defined as a "steady state" where an individual is in energy balance, i.e. the energy intake equals the energy expenditure, despite the low body weight and low body energy stores.

In the present study we faced a problem of defining malnutrition using any single tool. Using various nutritional parameters individually, prevalence of malnutrition varied between $22 \%$ (serum albumin) to $87 \%$ using TSF. Majority of the patients had very low fat $(55 \%$ severe depletion) and muscle mass (46\% moderate to mild depletion). As Indian standards are not available for fat and muscles mass, applying western values gave a very high prevalence of malnutrition in our study. This highlights the importance of having standards and cut-off points for Asian population which should be related more to functional parameters such as immune function, muscle function, clinical outcome or quality of life. Pham $\mathrm{NV}$ et al highlighted this in their study where they showed that large proportion of patients rated as moderate to severely malnourished based on subjective global assessment (SGA) had normal muscle mass and strength
[21].

BMI is the most widely used anthropometric index for the assessment of nutritional status in adults as it reflects the effect of both acute and chronic energy deficiency/ excess. The use of BMI as a measure of nutritional assessment is limited by its poor sensitivity with respect to baseline assessment, particularly for chronically undernourished as well overweight patients. For example those who are stunted and have low body weight may have normal BMI. Similarly, individuals in the highnormal range can undergo significant change in their nutritional status prior to estimation of having an abnormal status or being nutritionally depleted [18].

We observed $27(30 \%)$ of our patients had a BMI of less than 18.5. This high incidence is in contrast to the west where almost $30 \%$ of the population is overweight (BMI 25 to $29.9 \mathrm{Kg} / \mathrm{M} 2$ ) and another $30 \%$ is obese (BMI $>30 \mathrm{Kg} / \mathrm{M} 2)$ with only $5-7 \%$ patients having a BMI $<18.5$ [18]. Naidu and Rao observed that in certain areas of rural India up to $50 \%$ of the population with low incomes and land holdings suffer from chronic energy deficiency (CED) and have low BMI $\left(<18.5 \mathrm{Kg} / \mathrm{m}^{2}\right)$ [20]. Most of these are physiologically well adapted till 
the disease process starts.

In the present study, patients with a BMI of $<18.5$ had significantly greater derangement in their anthropometric, biochemical and immunological parameters including serum albumin. For example, all five patients with anergy in the study had a BMI $<18.5$. This may suggests that BMI could be a good tool for initial nutritional assessment especially in those with low BMI as has been observed by David E. Carney et al [18]. However, this could be erroneous as the cut-off was not chosen based on the function and a stunted population may still have adequate responses. Larger studies to define malnutrition based on cutoffs related to functional outcome rather than arbitrary cutoffs in surgical patients are required.

Serum albumin has been used classically in population studies as an indicator of visceral protein depletion [22]. In present study serum albumin revealed $77.52 \%$ of the patients to be normal although using anthropometric data majority of them were malnourished. This does not reflect the adequacy or deficiency of intake as many studies and years of clinical experience have shown us that undernourished patients do not become hypoalbuminemic until, and unless, they become ill. Additionally, ill patients may become hypoalbuminemic without being malnourished as serum albumin can be affected by acute onset illness due to circulatory inflammatory modulators despite normal or at least adequate nourishment.

Serum albumin has been found to be an indicator of inflammatory activity than a nutritional marker [7,22]. Inflammatory activity like surgery, leads to catabolism of body cell mass. In acute disease, hypoalbuminemia can develop quite rapidly, allowing body cell mass to be relatively well preserved. If successful recovery from acute trauma occurs without infection or residual necrotic tissue etc albumin levels rise rapidly in the second half of the first week after trauma but will be slow and will take months to recover completely. Thus albumin levels is a reliable sign of whether this inflammatory activity is diminishing or increasing, in other words whether the patient is getting better or worse [7]. This was observed to be true in our study as we observed a difference in outcomes based on changing albumin trends. Patients with falling or static albumin levels (Group I) had a significant decrease in all their nutritional parameters. Compared to this, patients with increasing albumin levels (Group II) gained significant weight and haemoglobin with improvement in various other nutritional parameters. This has also been observed by Visschers et al and who have used albumin as a marker of recovery from treatment, trauma or disease [23]. Haemoglobin also used as an inflammatory activity showed a similar trend but due to associated co-morbid conditions and failure to rule out other causes for anemia it limited its use for this pur- pose.

UNL, Nitrogen intake \& NB calculations are widely advocated as the best assessment tool for determining the adequacy of nutritional support $[9,10]$. The methods are simple, relatively inexpensive and can be done in any hospital. NB has been advocated as "the standard to which all other monitoring test should be compared". We found these to be useful tools for assessing the impact of various types of surgeries on nitrogen (muscle protein) losses in urine (UNL) and the dynamics of nutritional support by measuring nitrogen intake (NI) in preventing this loss.

The pattern of UNL \& NB showed that the peak proinflammatory activity due to surgical trauma was reached by D6 after which the anti-inflammatory responses gradually improved the UNL \& NB. Using the same method for assessing UNL in all patients, the losses varied based on the extent of surgery, for example it was enormously high in patients undergoing Mc Keown esophagectomy which involved thoracotomy and laparotomy. Assessment error or small sample size could have contributed to these high values. Despite this shortcoming, serial measurement does give an idea about the UNL.

Adequacy of nutritional support after surgery was assessed by studying the dynamics of effect of NI on UNL on different days. Nutritional support had no impact on these UNL till D2 after surgery as it was negatively associated. This could be due to strong pro-inflammatory response initiated by surgical trauma causing this obligate nitrogen loss. Subsequently, nutritional support helped in reversing this trend as NI became positively associated to UNL from D4 onwards becoming more positive till D11. This further reinforces the fact that why nutritional support is crucial as it helps in decreasing the UNL thereby sparing the muscle mass from breakdown. Similar to the trend in nutritional parameters, patients with rising albumin (Group II) showed improvement in their NB much earlier than Group I. From being in equally negative NB at beginning of the study, Group II became less negative from D4 onwards coming into positive NB by the end of the study on D11. Albumin which has traditionally been used as a marker of nutrition is a very reliable guide for monitoring the recovery of patient even in the first 7-10 days after surgery.

To conclude, nutritional assessment should address the fact that malnutrition implies and suggests that something is wrong and that surgery is likely to lead to diminished healing and complications. These adverse outcomes should dictate cut-offs rather those based on Western populations. It is suggested to collect a larger number of patients in future study and to correlate parameters of malnutrition (including functional parameters) to postoperative infectious morbidity and mortality. This 
would yield better cut-off points and more reliable assessment of numbers of patients being truly malnourished. Serum albumin is more reliable as an inflammatory marker and a guide for knowing that patient is recovering from surgery than as a nutritional marker. $\mathrm{Nu}$ tritional support postoperatively helps by decreasing UNL and NB improves better and earlier in patients with improving albumin levels.

Conflict of interest statement and funding: It is verified that there was no financial conflict of interest for all authors which includes any employment, consultancies, stock ownership, honoraria, paid expert testimony, patent applications/registrations, and grants or other funding by any agency in the study design, in the collection, analysis and interpretation of data; in the writing of the manuscript; and in the decision to submit the manuscript for publication. The following authors were part of the study.

Ravindra Singh Mohil, Nitisha Narayan, Namrata Singh, Asheesh Pravin Lal, Vishnubhatla Sreenivas, Dinesh Bhatnagar

Statement of Authorship: I also verify that all the authors have made substantial contributions to the above study by one or more of the following:

RSM: Conception and design of the study, analysis and interpretation of data.

$\mathrm{NN}$ : Acquisition of data, drafting the article

NS: Important intellectual content, statistical analysis and interpretation of data

APL: Acquisition of data, drafting the article

VS: Statistical analysis and data interpretation.

DB: final approval of the version to be submitted

All authors have read and approved the final manuscript and agreed to the contents.

I also verify that the manuscript, including tables has not been previously published and that the manuscript is not under consideration elsewhere.

\section{REFERENCES}

[1] Heymsfield, S.B., Tighe, A. and Wang, Z.-M. (1994) Nutritional assessment by anthropometric and biochemical methods. In: Shils, M.E., Olson, J.A. and Shike, M., Eds., Modern Nutrition in Health and Disease, Lea and Febiger, Malvern, 812-841.

[2] "BAPEN-Malnutrition Advisory Group: Guidelines for detection and management of malnutrition, Essex: BAPEN, 2000.

[3] Singh, H., Watt, K., Veitch, R., Cantor, M. and Duerksen, D. R., (2006) Malnutrition is prevalent in hospitalised medical patients: Are house staff identifying the malnourished patients?" Nutrition, 22, 352-354.

[4] Bavelaar, J.W., Otter, C.D., van Bodegraven, A.A., Thijs, A., VanBokhorst de Vander Scueren, M.A. (2008) Di- agnosis and treatment of a (disease-related) in hospital malnutrition: The performance of medical and nursing staff. Clinical Nutrition, 27, 431-438.

[5] Ben-Ishay, O., Gertsenzon, H., Mashiach, T., Kluger, Y., Chermesh, I. (2011) Malnutrition in Surgical Wards: A plea for Concern. Gastroenterology Research and Practice, 840512.

[6] Norman, K., Pichard, C., Lochs, H. and Pirlich, M. (2008) Prognostic impact of disease-related malnutrition. Clinical Nutrition, 27, 5-15.

[7] Soeters, P.B., Reijven, P.L., van Bokhorst-de van der Schueren, M.A., Schols, J.M., Halfens, R.J., Meijers, J.M. and van Gemert, W.G. (2008) A rational approach to nutritional assessment. Clinical Nutrition, 27, 706-716.

[8] Michael, L.C., Karen S., Stacy, J.B. and Marhew, W.L. (2006) Nitrogen balance, protein loss and the open abdomen. Critical Care Medicine, 35, 127-131.

[9] ASPEN Board of Directors and the Clinical Guidelines Task Force (2002) Guidelines for the use of parenteral and enteral nutrition in adult and pediatric patients. Journal of Parenteral and Enteral Nutrition, 26, 1SA-138SA

[10] Bistrian, B.R., Blackburn, G.L., Vitale, J., Cochran, d. and Naylor, J. (1976) Prevalence of malnutrition in general medical patients. Journal of the American Medical Association, 235, 1567-1570.

[11] Gopalan, C., Rama, B.V, Sastri, S.C., Balasubramaniam, B.S., Narasinga, R., Deosthale, Y.G. and Pant, K.C. (2002) Nutritive Value of Indian Foods.

[12] Hawk, P.B. and Oser, B.L. (1976) Urinary Creatinine excretion and lean body mass. The American Journal of Clinical Nutrition, 29, 1359.

[13] Herendon, D.N. (1981) Nutritional assessment in surgical patients. In: Yaraborough, M.F. and Curreri, P.W. Eds., Contemporary Issues in Clinical Nutrition, 1-11.

[14] Krishnan Das, K.V. (1980) Nutritional anemias in India. Journal of Association of Physicians of India, 28, 521.

[15] Grant, J.P., Custer, P.B. and Thurlow, R.D. (1981) Current techniques of nutritional assessment. Surgical Clinics of North America, 61, 437.

[16] Palmar, D.L. and Read, W.P. (1974) Delayed hypersensitivity skin testing: Clinical correlates and anergy. Journal of Infectious Diseases, 130, 138.

[17] Leardi, S., Altilia, F., Delmonaco, S., Cianca, G., Pietroletti, R. and Simi, M. (2000) Blood levels of cholesterol and postoperative septic complications. Annali Italiani Di Chirurgia, 71, 233-237.

[18] David, E.C. and Michael, M.M. (2002) Current concepts in nutritional assessment. Archives of Surgery, 137, 4245.

[19] Lochs, H., Allison, S.P., Meir, R., Pirlich, M., Kondrup, J., Schneider, S., van den Berghe G. and Pichard, C. (2006) Introductory to the ESPEN guidelines on enteral nutrition: Terminology, definitions and general topics. Clinical Nutrition, 25, 180-186.

[20] Naidu, A.N. and Rao, N.P. (1994) Body mass index: A measure of the nutritional status in Indian populations. European Journal of Clinical Nutrition, 48, 1994, S131140.

[21] Pham, N.V., Cox-Reijven, P.L., Wodzig, W.K., Greve, J.W. and Soeters, P.B. (2007) SGA and measures for muscle mass and strength in surgical Vietnamese patients. Nutrition, 23, 283-291. 
[22] Banh, L. (2006) Serum proteins as markers of nutrition: What are we treating? Practice Gastroenterology, 30, 46-64.

[23] Visschers, R.G., Olde Damink, S.W., Winkens, B., Soeters,
P.B. and van Gemert, W.G. (2008) Treatment strategies in 135 consecutive patients with enterocutaneous fistulas. World Journal of Surgery, 32, 445-453. 